\title{
Study of Virulence Factors in Escherichia coli Isolated from Skin and Soft Tissue Infections
}

\author{
R. Saraswati Jayanthi ${ }^{{ }^{*}}$ and K. Soumya ${ }^{2}$ \\ ${ }^{1}$ Department of Microbiology, ESIC Medical College, Sanathnagar, Hyderabad, Telangana, India \\ ${ }^{2}$ Department of Microbiology, Shridevi Institute Of Medical Sciences and Research Hospital, \\ Tumkur, Karnataka, India \\ *Corresponding author
}

\begin{tabular}{|c|c|}
\hline & A B S T R A C T \\
\hline & $\begin{array}{l}\text { Escherichia coli are normal commensals of the intestinal tract. But have been implicated to } \\
\text { cause urinary tract infections, wound infections, septicaemias and neonatal meningitis. } \\
\text { Extra-intestinal pathogenic Escherichia coli (ExPEC), the specialized strains of } E \text { coli that } \\
\text { cause most extra-intestinal E. coli infections, represent a major but little appreciated health }\end{array}$ \\
\hline Keywords & $\begin{array}{l}\text { threat. The present study aimed at characterising the extra intestinal pathogenic E. coli } \\
\text { (ExPEC) other than UPEC (UropathogenicE. coli) and to correlate their virulence factors }\end{array}$ \\
\hline $\begin{array}{l}\text { SSTI, ExPEC, } \\
\text { Virulence factors. }\end{array}$ & $\begin{array}{l}\text { with the clinical diagnosis and these with isolates from stool samples. The antibiotic } \\
\text { susceptibility pattern in these isolates was also reviewed. The study was conducted at }\end{array}$ \\
\hline Article Info & $\begin{array}{l}\text { Dept. of Microbiology. } 50 \text { consecutive isolates of } E \text {. coli from wound swabs or pus } \\
\text { collected from skin and soft tissue infections were characterised. These isolates were }\end{array}$ \\
\hline $\begin{array}{l}\text { Accepted: } \\
\text { xx June } 2017 \\
\text { Available Online: } \\
\text { xx July } 2017\end{array}$ & $\begin{array}{l}\text { screened for colony morphology, serum resistance, haemolysin production, gelatin } \\
\text { hydrolysis, cell surface hydrophobicity, and haemagglutination, ESBL and antibiotic } \\
\text { profile. Out of } 50 \text { isolates from SSTI, } 6(12 \%) \text { were haemolytic, } 16(32 \%) \text { formed mucoid } \\
\text { colony and } 32(68 \%) \text { were non mucoid, } 16(32 \%) \text { were serum resistant, } 3(6 \%) \text { produced } \\
\text { gelatinase, } 12(24 \%) \text { were hydrophobic, } 37(74 \%) \text { produced mannose sensitive }\end{array}$ \\
\hline & $\begin{array}{l}\text { haemagglutination \& } 13(26 \%) \text { mannose resistant haemagglutination and } 80 \% \text { were } \\
\text { multidrug resistant. E. coli is commonly isolated from SSTI but their importance as } \\
\text { etiological agents in these infections is questionable. The present study does demonstrates } \\
\text { the virulence potential in the E. coli strains isolated from SSTI. There is a need to further } \\
\text { study the virulence factors of these ExPEC (Extra intestinal pathogenic E. coli) in more } \\
\text { number of isolates and with the use of molecular techniques. }\end{array}$ \\
\hline
\end{tabular}

\section{Introduction}

Skin and soft tissue infections (SSTIs) result from microbial invasion of the skin and its supporting structures and its one of the common infections in patients of all age group. SSTIs may be simple or complicated or suppurative or non suppurative (Ramakrishnanan et al., 2015). Extra intestinal pathogenic Escherichia coli
(ExPEC), the specialized strains of $E$ coli that cause most extra intestinal $E$. coli infections represent a major health threat as they cause infections of urinary tract, the central nervous system, the circulatory system, respiratory system also (Johnson, 2001). Escherichia coli strains are frequently isolated from SSTIs and in one study it was showed that it is the $3^{\text {rd }}$ 
ranked pathogen after $S$. aureus and Pseudomonas aeruginosa (Petkovsek et al., 2009). Therefore $E$. coli isolates from SSTIs merit detailed study of their virulence potential especially taking into account the dramatic decline in antibiotic susceptibility of these isolates in recent years. E. coli has many virulence mechanisms like toxins, enzymes, fimbriae, capsule, serum resistance, cell surface hydrophobicity and aerobactin. The incidence of $E$. coli strains which are multidrug resistant has been steadily increasing over the past few years resulting in limitations of therapeutics options (Asma Banu et al., 2011).

The present study aimed at characterizing $E$. coli isolates from SSTIs, to correlate with the virulence factors and to also compare these with isolates from stool samples.

\section{Materials and Methods}

The study was conducted in Microbiology laboratory of St. John's Medical College \& Hospital after prior permission from the appropriate authorities. A total of 50 isolates of $E$. coli from SSTIs and 15 isolates from other extra intestinal infections, 5 uropathogenic E. coli and 10 isolates from stool samples were included in the study. Specimen received were pus, wound swabs for SSTIs, for other extra intestinal infections (sputum, catheter tips, genital swabs, ocular or body fluids etc), stool and urine. The samples were processed using standard operating procedures.

The isolates were identified based on Gram stain, colony morphology on blood agar, MacConkey's agar and standard biochemical tests. Colony morphology, haemolysin production, serum resistance, gelatinase production, cell surface hydrophobicity, haemagglutination were studied in the all 75 isolates.

\section{Detection of virulence factors}

\section{Colony morphology}

We documented whether the colonies were mucoid or non mucoid on either BA or MA as mucoid nature may also enhance virulence of the isolate Haemolysin production: Hamolysis is caused by the cytolytic protein toxin also known as alpha haemolysin (Cavalieri, 1984). Isolates were inoculated onto $5 \%$ sheep blood agar and incubated overnight at $37^{\circ} \mathrm{C}$. Haemolysin production was detected by the presence zone of complete haemolysis.

\section{Serum resistance or serum bactericidal assay}

It was studied by using fresh cultures. Overnight cultures of $E$. coli were grown in blood agar were harvested and suspended in Hank's balanced salt solution. $50 \mu \mathrm{l}$ of bacterial suspension was incubated with $50 \mu 1$ of pooled serum samples in microtitre plate. It was incubated in shaker water bath for $3 \mathrm{hrs}$. $10 \mu \mathrm{l}$ was withdrawn at $0 \mathrm{hrs}$ and after $3 \mathrm{hrs}$ and plated on nutrient agar and read after $18 \mathrm{hrs}$. If counts dropped to $1 \%$ of initial count it was considered susceptible and resistant if more than $90 \%$ of organism survived after $3 \mathrm{hr}$ (Raksha, 2003).

\section{Cell surface hydrophobicity}

It was performed by salt aggregation test (SAT). $40 \mu \mathrm{l}$ of bacterial suspension in phosphate buffer saline $(6.8 \mathrm{pH})$ was mixed with equal volume of different molar concentration of ammonium sulphate i.e., from $1 \mathrm{M}, 1.4 \mathrm{M}$ and $2 \mathrm{M}$ on a glass slide and observed after 1 min (Siegfried L1994). The highest dilution of ammonium sulphate solution showing visible clumping of bacteria was scored as salt aggregative value. SAT value of $1.14 \mathrm{M}$ was considered as auto aggregative, if SAT value was less than 1.14 
M then hydrophobic. Those which aggregated with salt particles and formed clumps were considered hydrophobic. A strain of E. coli which was haemolytic, MRHA (mannose resistant haemagglutination) positive and consistently positive for cell surface hydrophobicity was used as positive control. A strain which was non lytic, negative for MRHA and consistently negative for cell surface hydrophobicity was used as negative control.

\section{Haemagglutination}

Bacteria cause agglutination of RBCs in the presence of special structures like fimbriae. Haemagglutination was detected by clumping of erythrocytes by fimbriae of bacteria in presence of D mannose (Siegfried, 1994). E. coli was inoculated into Mueller Hinton broth and incubated for 5 days to get fimbriae rich E. coli.

The pellicle was then sub-cultured on colonization factor antigen agar (CFA agar) and incubated overnight. 3\% washed RBC (A blood grp) in PBS was prepared. $40 \mu 1$ of $3 \%$ mannose and $40 \mu 1$ of RBC was added on to VDRL slide and a single colony was picked from the CFA and mixed with the above and rotated on a VDRL plate for 4 minutes and observation recorded. ATCC E. coli 25922 for mannose sensitive haemagglutination (MSHA) and UPE serotypes 06 and 011 were used as MRHA positive controls

\section{Gelatinase production}

Gelatinase production was tested using gelatin agar. The slope was inoculated with test organism and incubated $37^{\circ} \mathrm{C}$. Liquefaction was taken as positive test. We also tried to quantitate the E. coli in terms of growth on blood and MacConkey agar plates and categorised it as scanty growth if growth only in primary streak, moderate growth if growth present in secondary streak also) and heavy growth if growth is present all throughout the streak line.

\section{Antibiotic susceptibility testing}

The antibiotic susceptibility was done using modified Kirby Bauer disc diffusion method. The antibiotic tested were gentamicin $(10 \mu \mathrm{g})$, amikacin $(30 \mu \mathrm{g})$, netilmycin $(30 \mu \mathrm{g})$, tetracycline $\quad(30 \mu \mathrm{g}), \quad$ cotrimoxazole $(1.25 / 23.75 \mu \mathrm{g}), \quad$ ciprofloxacin $\quad(5 \mu \mathrm{g})$, ampicillin $(10 \mu \mathrm{g})$, piperacillin $(100 \mu \mathrm{g})$, cefuroxime $(30 \mu \mathrm{g})$, cephalexin $(30 \mu \mathrm{g})$, ceftazidime $(30 \mu \mathrm{g})$, cefotaxime $(30 \mu \mathrm{g})$, cefoperazone $(75 \mu \mathrm{g})$, and cefoperazone plus sulbactum combination $(75 / 30 \mu \mathrm{g})$. After $18 \mathrm{hrs}$ of incubation at $37^{\circ} \mathrm{C}$, the diameter of the zone of inhibition was measured using a millimeter scale and interpreted

\section{ESBL production}

It was done by Double Disk synergy test, synergy was determined between a disc of augmentin $(20 \mathrm{mg}$ amoxycillin and $10 \mathrm{mg}$ clavulanic acid) and a $30 \mathrm{mg}$ disc of three 3GC test antibiotic (cefipime, cefotaxime and ceftazidime disc) around it placed at a distance of $30 \mathrm{~mm}$ apart on a lawn culture of the resistant isolate under test on MuellerHinton Agar (MHA, Hi-Media). The test organism was considered to produce ESBL, if the zone size around the test antibiotic disc increased towards the augmentin disc.

\section{Results and Discussion}

A total of 80 strains were tested for virulence factors. 50 of these were isolated from extraintestinal infections, 10 from stool, 5 from urinary tract infections and 15 from others extraintestinal infections. 6 virulence factors were studied in all 80 isolates.

Out of the 50 ExPEC isolates, 39 isolates showed one or more than virulence factors, among these 39 isolates; 19 showed at least 
one virulence factor, 13 showed two virulence factors, five showed three virulence factors and two showed 4 virulence factors. Only 11 isolates did not show any virulence factors.In the $50 \mathrm{SSTI}$ isolates most common virulence factor was serum resistance $17(34 \%)$, followed by formation of mucoid colony $16(32 \%)$, MRHA 13(26\%),10(20\%) isolates were hydrophobic, haemolysin produced in only 6(12\%) and gelatinase in 3(6\%) (Fig. 1).

Stool isolates only showed presence of serum resistance in 2 isolates and cell surface hydrophobicity in one Table 1 . Out of the 15 extra intestinal $E$. coli infections other than SSTIs serum resistance $(70 \%)$ was the most common virulence factor, followed by cell surface hydrophobicity present in $50 \%$ isolates and haemolysis, presence of mucoid colonies, and Mannose resistant haemagglutination present $33 \%$ present isolates SSTI comprised of the following infections diabetic foot swabs $(22 \%)$, surgical site infections (SSI 20\%), wound swabs (18\%), pus from abscess (16\%),ulcer swabs $(10 \%)$ and other miscellaneous infections.

When we correlated the presence of virulence factors in $E$. coli with the disease condition we found that in SSI it was $90 \%$, miscellaneous infections it was $94 \%$, in wound swabs $78 \%$, from abscess it was $7 \%$, diabetic foot lesions $42 \%$ and with ulcers it was $40 \%$ (Fig. 2). In terms of growth out of the 50 isolates of ExPEC 56\% showed heavy growth, $30 \%$ scanty and 14\% moderate growth. Out of 50 isolates, 26 were pure growths and 24 grew along with other bacteria. Out of 24 co-infections Enterococcus (7), Proteus mirabilis (5), Klebsiella/Enterobacter (4), Pseudomonas aeruginosa (3), beta haemolytic Streptococci (3), Staphylococcus aureus (1), and non fermenting gram negative bacilli (1) (Table 2).

The isolates from SSTIs showed maximum sensitivity to cefoperazone plus sulbactam
(94\%) combination followed by amikacin (74\%), netilmycin (72\%), gentamicin $(50 \%)$. They were least sensitive to tetracycline, 12\%, Ciprofloxacin 12\%, Ampicillin $12 \%$, piperacillin $8 \%$ and third third cepahosporin $10 \%$. Extended spectrum beta lactamase (ESBL) producing strains were 12 among the 50 ExPEC.

Among ESBL producers, only one isolate did not show presence any virulence factor, 6 showed presence of at least one virulence factor, 4 presence of two factors and one the presence of three virulence factors. Extra intestinal pathogenic Escherichia coli (ExPEC) is the most common gram negative bacterial pathogen and cause a wide range of infections. Global mortality and morbidity rates due to ExPEC are substantial and increasing (Poolman Jan and Wicker Michael, 2016). The capacity of E. coli to produce many virulence factors contributes to its pathogenicity (Sharma, 2007). ExPEC strains in comparison to commensal E. coli strains have larger genomes and encode more virulent factors (Micenkova, 2016).

The present study reveals that $78 \%$ of SSTIs causing $E$. coli isolates produced one or more virulent factor when compared to the normal commensal E of intestine. Serum resistance helps bacteria escape the complement mediated killing our study showed that $34 \%$ of strains were serum resistant.

About 32\% strains produced mucoid colonies which in turn translate into increased virulence. $26 \%$ isolates produced MRHA which suggests enhanced adhering potential. Haemolysin production is associated with severe forms of infection and in our study few strains about 6 isolates produced haemolysin (Jhonson, 1991). Cell surface hydrophobicity promotes adherence to various surfaces, $20 \%$ of SSTI $E$. coli isolates were hydrophobic. 
Table.1 Showing virulence factors in Escherichia coli isolated from stool and SSTIs

\begin{tabular}{|l|l|l|l|l|l|l|}
\hline Sl.No & Haemolysin & $\begin{array}{l}\text { Mucoid } \\
\text { colonies }\end{array}$ & $\begin{array}{l}\text { Serum } \\
\text { Resistance }\end{array}$ & Gelatinase & $\begin{array}{l}\text { Cell surface } \\
\text { Hydrophobicity }\end{array}$ & $\begin{array}{l}\text { MRHA } \\
\text { (Hamem } \\
\text { agglutination) }\end{array}$ \\
\hline Stool & 0 & 0 & $20 \%$ & 0 & $10 \%$ & 0 \\
\hline ExPEC & $12 \%$ & $32 \%$ & $34 \%$ & $6 \%$ & $20 \%$ & $26 \%$ \\
\hline
\end{tabular}

Table.2 Co-infections with $E$. coli infections

\begin{tabular}{|l|l|l|}
\hline Organism & Number & Type of growth \\
\hline B lytic Streptococci & 3 & $\mathrm{Sg}$ \\
\hline Enterococcus & 7 & $6-\mathrm{Sg} \& 1-\mathrm{Hg}$ \\
\hline Proteus mirabilis & 5 & $1-\mathrm{Sg} \& 4-\mathrm{Hg}$ \\
\hline Pseudo aeruginosa & 3 & $1-\mathrm{Sg} \& 2-\mathrm{Hg}$ \\
\hline S. aureus & 1 & $\mathrm{Hg}$ \\
\hline Klebsiella/Enterobacter & 4 & $2-\mathrm{Sg} \&$ 2-Hg \\
\hline Nfgnb & 1 & $\mathrm{Hg}$ \\
\hline & Total-24 & $\begin{array}{l}\mathrm{Sg} \text { - Scanty growth } \\
\mathrm{Hg} \text { - Heavy growth }\end{array}$ \\
\hline
\end{tabular}

Fig.1 Virulence factors in E. coli isolated from SSTIs

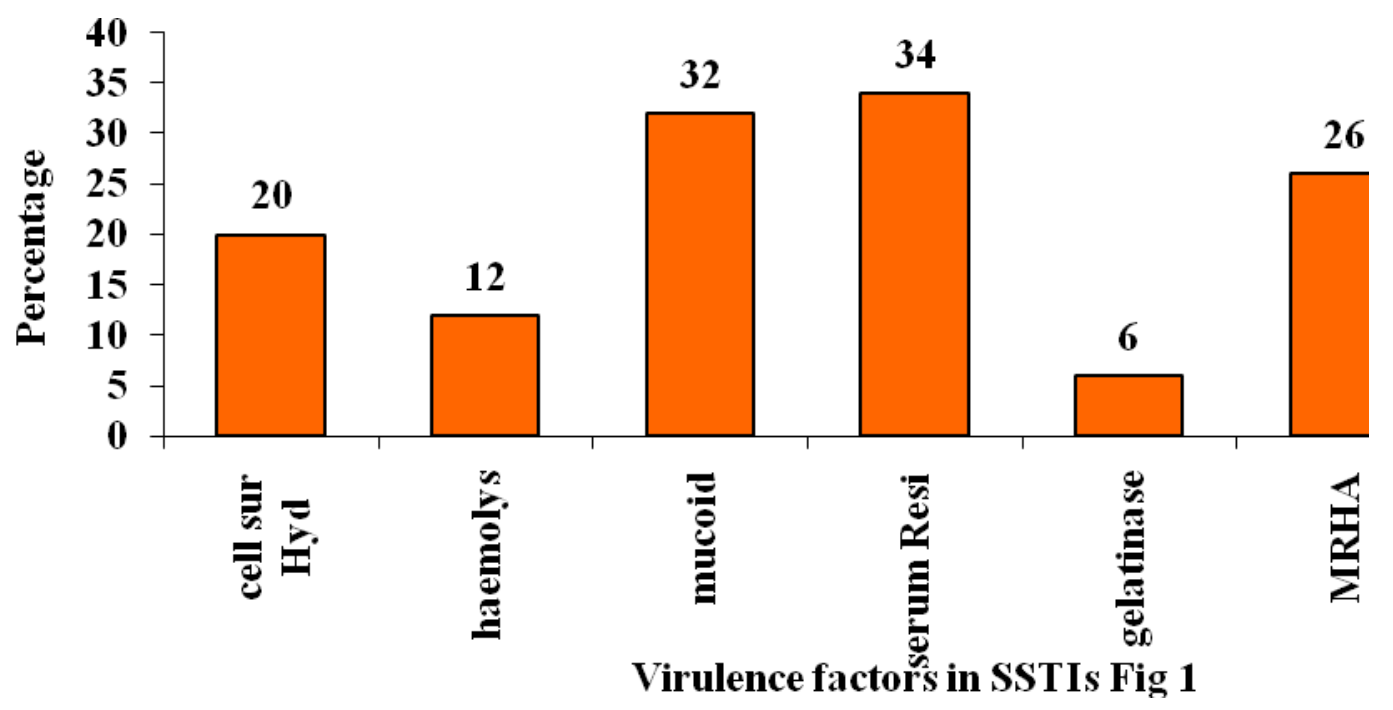


Fig.2 Correlation between diseases and virulence factor among SSTIs

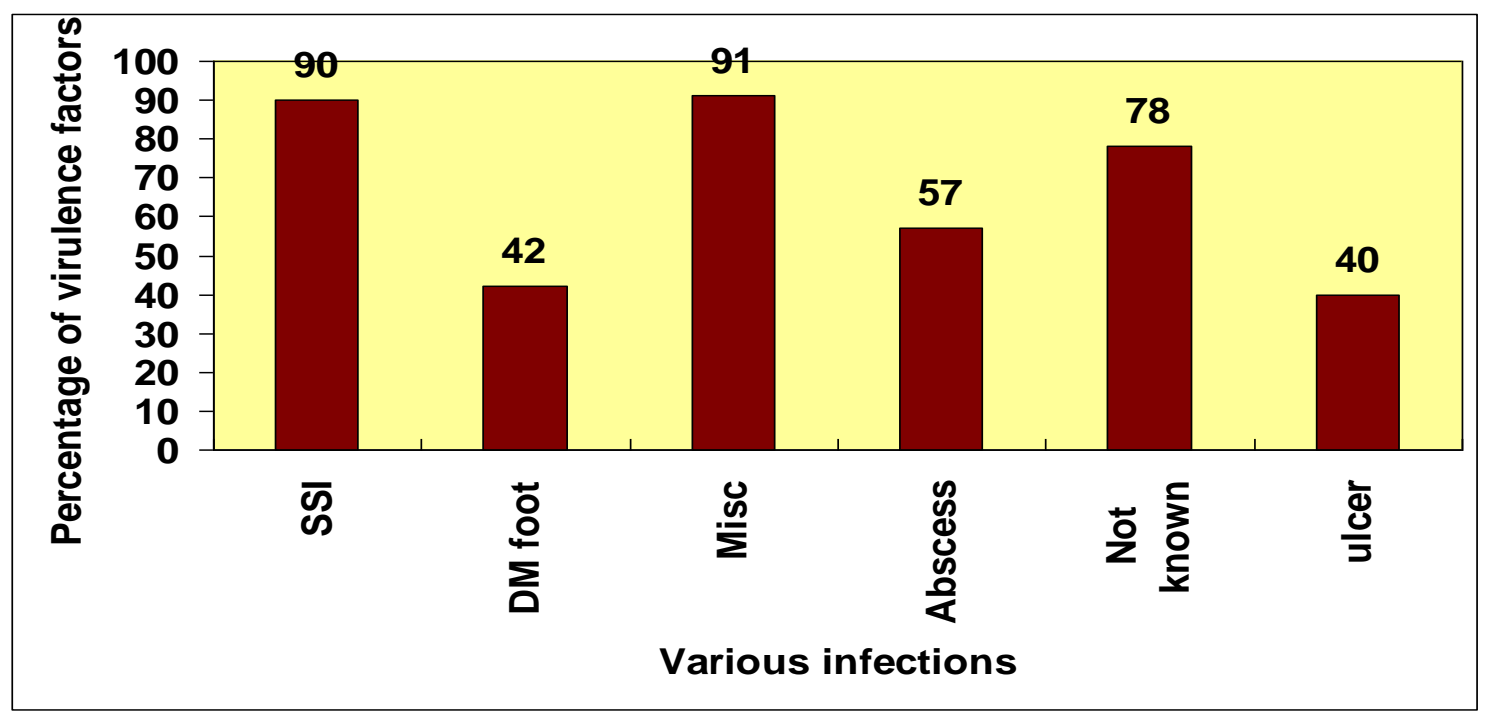

When the virulence factors were correlated with clinical diagnosis the least percentage of virulence factors were seen in DM foot and ulcers. Strains which had no virulence factors, out of them $90 \%$ showed heavy growth on plate, in 4 of them known pathogens were isolated. Therefore the growth pattern alone cannot be considered as significant while reporting.

Antibiotic susceptibility was studied in all 50 isolates of extra inteinal E. coli. Resistance was observed commonly used antibiotics like tetracycline. Ciprofloxacin, Ampicillin, Piperacillin and also among third generation Cephalosporins. $92 \%$ of strains which produced ESBL had one or more than one virulence factors. Virulence factors and antibiotic resistance may confer increased fitness for extra intestinal infections, they may do so by via mutually exclusive pathways and in distinct population (Emody, 2003). The present study was undertaken because though there are many studies that have been done to characterize UPEC and ExPEC, no study especially deals with SSTIs exclusively although E. coli is very commonly isolated in skin and soft tissues infection. There are some drawback in our study it's just a pilot study, more number of isolates need to be studied and statistical analysis was not possible due to small sample size. Molecular methods should be used to study the virulence potential of these isolates.

\section{References}

Asma Banu, et al. 2011. Extraintestinal Infections due to Escherichia coli; An Emerging issue. J. Clin. Diag. Res., 5(3): 486-490.

Cavalieri, S.J., Bohach, G.A., Snyder, I.S. 1984. Escherichia coli alpha haemolysin: characteristics and probable role in pathogenicity. Microbiol. Rev., 48: 326- 343.

Emody, L., Kerenyi, M., Nagy, G. 2003. Virulence factors of uropathogenic Escherichia coli. Int. J. Antimicrob. Agents, 22: 29-33.

Jhonson, J.R. 1991. Virulence factor in $E$. coli urinary tract infection. Clin. Microbiol. Rev., 14: 81-8.

Johnson, J.R., Russo, T.A. 2001. Esxtraintestinal pathogenic Escherichia coli: "The other bad E. coli". J. Lab. Clin. Med., 139: 155-162. 
Micenkova, L., Bosak, J., Vrbe, M., Sevcikova, A. \& Smajs, D. Human extraintestinal pathogenic Escherichia coli strains differ in prevalence of prevalence factors, phylogroup, and bacteriocin determinants. BMC Microbiol., 16: 218-226.

Petkovseketal. 2009. Virulence potential of Escherichia coli isolates from skin and soft tissue infection. J. Clin. Micro., 47(6): p1811-1817.

Poolman Jan, T. \& Wicker Michael. 2016. Extraintestinal pathogenic Escherichia coli, a common Human pathogen; challenges for Vaccine Development and Progress in the field. J. Infect. Dis., 213-225.

Raksha, R., Srinivasa, H., Macaden, R.S. 2003. Occurrence and characterization of uropathogenic Escherichia coli in urinary tract infections. Indian J. Med. Microbiol., 21: 102-7.

Ramakrishnan, K., Salinas, C., Robert Higuta, N.I.A. 2015. Skin and soft tissue Infections. American Family Physician, 92(6): 474-483.

Sharma, S., Bhat, G.K., Shenoy, S. 2007. Virulence factors and drug resistance in E. coli isolated from extra intestinal infections. Indian J. Med. Microbiol., 25(4): 369-73.

Siegfried, L., Kmetova, M., Puzova, H., Molokacova, M., Filka, J. 1994. Virulence associated factors in Escherichia coli strains isolated from children with urinary tract infections. $J$. Med. Microbiol., 41: 127-32.

\section{How to cite this article:}

Saraswati Jayanthi, R. and Soumya, K. 2017. Study of Virulence Factors in Escherichia coli Isolated from Skin and Soft Tissue Infections. Int.J.Curr.Microbiol.App.Sci. 6(7): 2288-2294. doi: https://doi.org/10.20546/ijcmas.2017.607.269 